\title{
Jarritos metálicos con tapadera y asa acodada de Al-Andalus (siglos XII-XIII d.C.)
}

\author{
Metalic ewers with lid and angled hand from Al-Andalus (12-13 $3^{\text {th }}$ centuries)
}

\author{
Rafael Azuar Ruiz ${ }^{1}$ \\ Recibido: 03/12/2018 - Enviado a Evaluación: 17/12/2018 - Aprobado: 28/01/2019
}

\begin{abstract}
RESUMEN
Presentamos el inventario y estudio de los jarritos con tapadera aparecidos en al-Andalus. Son de tipo piriforme con asa acodada y tapadera, y tienen un característico collar abultado en sus cuellos. Sus cuerpos están facetados verticalmente o con una decoración incisa elipsoidal. Sus precedentes son los jarritos fatimíes de tradición copta, de los siglos X-XI y son una muestra de la metalistería andalusí de los siglos XII-XIII.
\end{abstract}

Palabras clave: Islámico, Almorávide, Almohade, Fatimí, Córdoba

A Juan Zozaya por descubrirme el mundo de la metalistería andalusí

Han transcurrido setenta años desde que Pedro de Palol Salellas publicara su estudio monográfico sobre los Bronces hispano-visigodos de origen mediterráneo: Jarritos y patenas litúrgicas, en el que, como continuación o epílogo de los jarritos visigodos, incluyó un apartado dedicado a los "Jarros califales de origen copto" (PALOL, 1950:82-84), en cuyo título se explicita su propuesta cronológica para estos jarritos como califales o del siglo $X$ y con precedentes formales en el arte copto de Egipto. En el mismo texto y en su nota $n^{\circ} 3$ agradece la colaboración y la información aportada por D. Manuel Gómez-Moreno quien le había permitido consultar el capítulo que había escrito sobre el "Arte Califal" para el tercer volumen del Ars Hispaniae. Sin embargo y sorprendentemente, en el texto publicado no aparecía referencia alguna a estos jarritos de bronce (GÓMEZ-MORENO, 1951). Sería más tarde cuando Leopoldo Torres Balbás incluyó estos jarritos

\begin{abstract}
We present the inventory and study of the ewers with lid found in al-Andalus. These ewers are piriform type with angled handle and lid, and has the collar moulding in their necks. Their bodies are facetted vertically or with an ellipsoidal incised decoration. Its precedents are the Fatimid ewers from Coptic tradition, of the centuries X-XI, and are a sample of the Andalusian metalwork from the XII-XIII centuries.
\end{abstract}

Key words: Islamic, Almoravid, Almohad, Fatimid, Córdoba

en el capítulo dedicado al "Arte Hispanomusulmán hasta la caída del califato de Córdoba” de la España Musulmana, aparecido en 1957 (TORRES, 1987:762-764). Desde entonces y hasta ahora estos jarritos no han merecido el interés de los investigadores españoles.

\section{JARRITOS CON TAPADERA Y ASA ACODADA DE AL-ANDALUS}

El inventario y listado que presentamos asciende a un total de siete jarritos, dos más de los publicados en su día por Pedro de Palol (1950: 82-84) en cuyo mencionado estudio recogía y aportaba información sobre cuatro ejemplares de origen Peninsular y otro procedente de Baleares. Los ejemplares son los siguientes:

\section{I.1. Jarrito de la colección Manuel Gómez-Moreno}

Su base es plana con estrechamiento en su pie que marca su forma "bulbiforme"2, cuerpo

\footnotetext{
1. MARQ. Museo Arqueológico de Alicante

2. Término no recogido en el diccionario de la RAE, pero utilizado por Pedro de Palol para describir la forma genérica de estos jarritos
} 


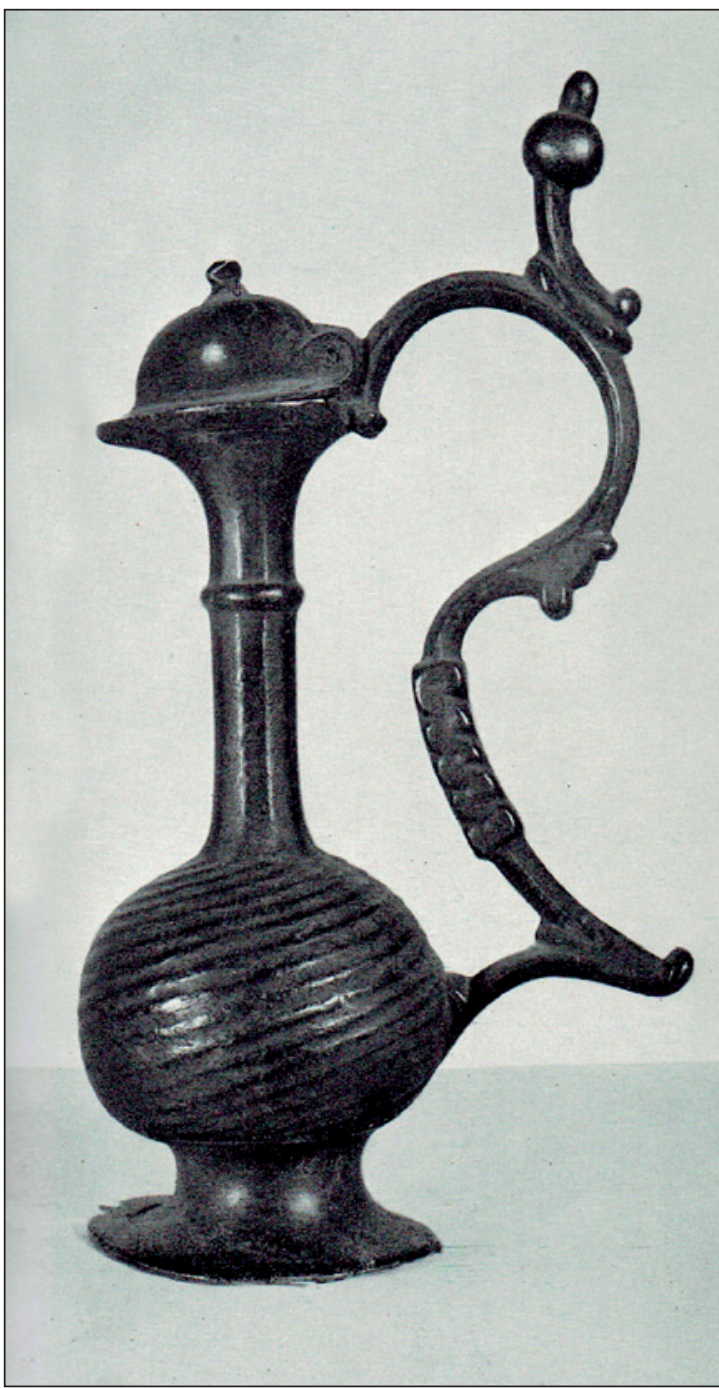

Figura 1. Jarrito de la colección de M. Gómez-Moreno (reproducción de la Lm. LIII, del catálogo de la Exposición Antológica del Tesoro Documental, Bibliográfico y Arqueológico de España, Madrid (1959: 107, $n^{\circ}$ 146).

decorado con estrías incisas acanaladas elipsoides, cuello cilíndrico, estrecho, alto y facetado con un anillo engrosado en su parte alta. Se remata con un borde abierto y boca almendrada. Su tapadera se sujeta al asa por medio de una charnela y con un botón de remate en su parte superior. El asa presenta un codo más marcado en su arranque. Continúa en perfil en "s", de sección ligeramente romboidal, con asidero prismático en su parte inferior con decoración serpenteante o de cinco círculos enlazados y en relieve. En el arranque de la curva del asa existe un pequeño bulbo y en su parte superior se desarrolla un apéndice, a modo de ave, de cabeza esférica rematada con un botón (PALOL, 1950: 82-3, Lm. XLII-2) (fig. 1).

La pieza no fue publicada por M. Gómez-Moreno aunque sí la donó al Museo Arqueológico Provincial de Granada en 1952, como dejó testimonio su directora Joaquina Eguaras en las Memorias de los Museos Arqueológicos Provinciales, en donde aparece como la número 22 de la lista de las piezas visigodas donadas (1952-1953: 46, Lm. XII). Posteriormente, en 1959, fue exhibida en la Exposición Antológica del Tesoro Documental, Bibliográfico y Arqueológico de España, organizada en conmemoración del centenario del Cuerpo Facultativo de Archiveros, Bibliotecarios y Arqueólogos en Madrid, en la que aparece como un "Jarro de Bronce" de Arte Califal (S. X) y depositado en el Museo Arqueológico Provincial de Granada, con $n^{\circ}$ Inv. 4430, de una altura total de 20,5 cm (Madrid, 1959: 107, n 146, Lm. LIII). Revisando la ficha proporcionada por la dirección del Museo $^{3}$ se comprueba que este número es el registro de entrada en propiedad del museo, mientras que el número de inventario general es el 2796. Así también, las dimensiones del jarrito son $17 \mathrm{~cm}$ de altura, desde su base al botón de su tapadera, diámetro de su base $6,2 \mathrm{~cm}$ y del cuerpo $6,8 \mathrm{~cm}$.

\section{I.2. Jarrito de Alcolea, Córdoba (fig. 2)}

La otra pieza que recoge es un jarrito de un tamaño inferior, de forma similar o idéntica, es decir base plana, con estrechamiento en su pie, cuerpo globular o "bulbiforme" con decoración incisa de estrías acanaladas elipsoides, cuello cilíndrico, estrecho, alto y facetado, con collar abultado en su parte alta. A diferencia del anterior, su borde está soldado a la tapadera, adquiriendo la forma de una cabeza de ave

(PALOL, 1950:82)

3. Agradecemos al director del museo, Isidro Toro Moyano, el habernos facilitado copia de la ficha original debida a Da Joaquina Eguaras, así como los datos necesarios sobre la pieza. 


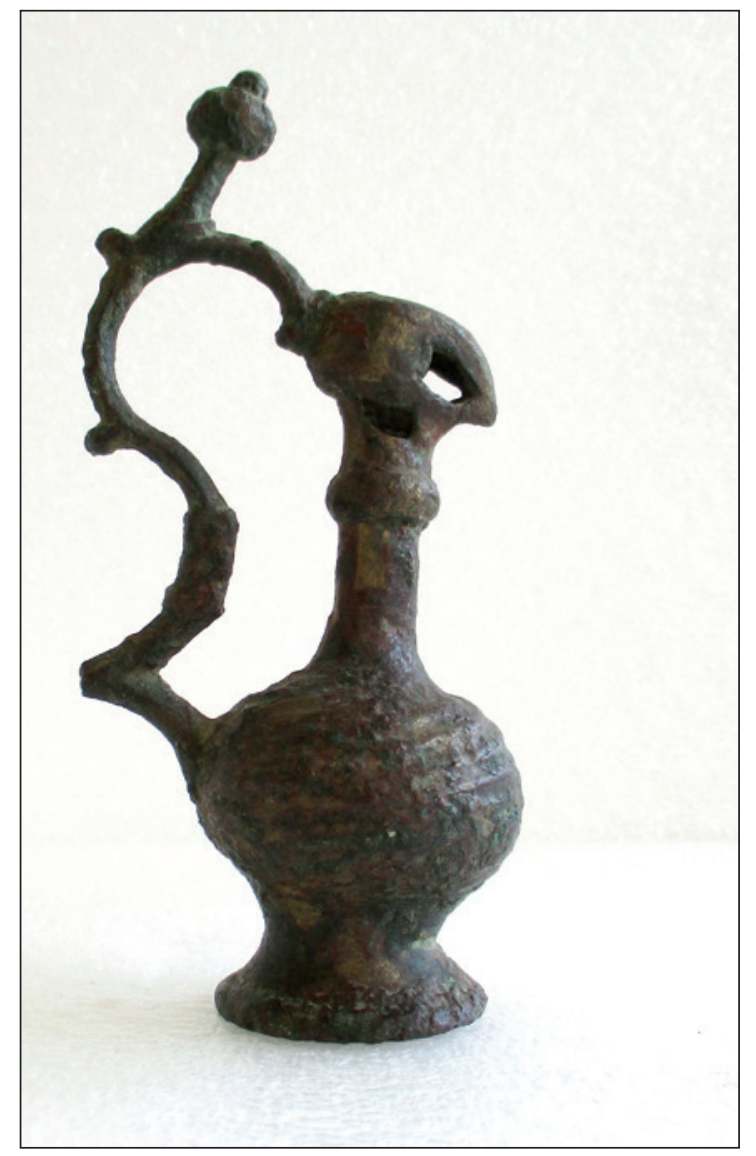

Figura 2. Jarrito de Alcolea (Museo Arqueológico y Etnográfico de Córdoba. Archivo Fotográfico).

con dos ojos u orificios laterales. Por el contrario, el desarrollo del asa es similar, así como el tratamiento de sus apéndices y remate "aviforme"4 (PALOL, 1950:83, Lm.: XLII-1). Su fotografía fue publicada, sin comentario en el texto, por L. Torres Balbás en 1957 (1987:763, f. 621). El jarrito, según información facilitada por la directora del museo ${ }^{5}$, ingresó en el Museo Arqueológico y Etnográfico de Córdoba en el año 1941, adquirido a D. Juan Rodríguez Mora por 25 pts., quién aseguró apareció en "Huerta Alcolea", Córdoba. Sus dimensiones son altura $10,5 \mathrm{~cm}$ y con el asa $14,2 \mathrm{~cm}$, diámetro de la base $3,9 \mathrm{~cm}$ y del cuerpo $4,8 \mathrm{~cm}$. Número de inventario CE007413. Se encuentra en mal estado de conservación.

\section{I.3. Asa del Instituto Valencia de Don Juan (fig. 3)}

Procedente de Segura de la Sierra (Jaén) y comprada en 1945 (NEBREDA, 2017: 609) es el asa conservada y expuesta en la colección del Instituto Valencia de Don Juan de Madrid ${ }^{6}$, con $\mathrm{n}^{\circ}$ inv. 3089, cuyas dimensiones son $15,5 \mathrm{~cm}$ de altura, $6 \mathrm{~cm}$ de ancha y una sección de 1,8 cm. Su tapa es de 4,8 cm de diámetro de base y $2,8 \mathrm{~cm}$ de altura. El asa es similar a las de las piezas anteriormente descritas, supera en altura al remate de la tapadera, pero con la diferencia de que al llegar el asa

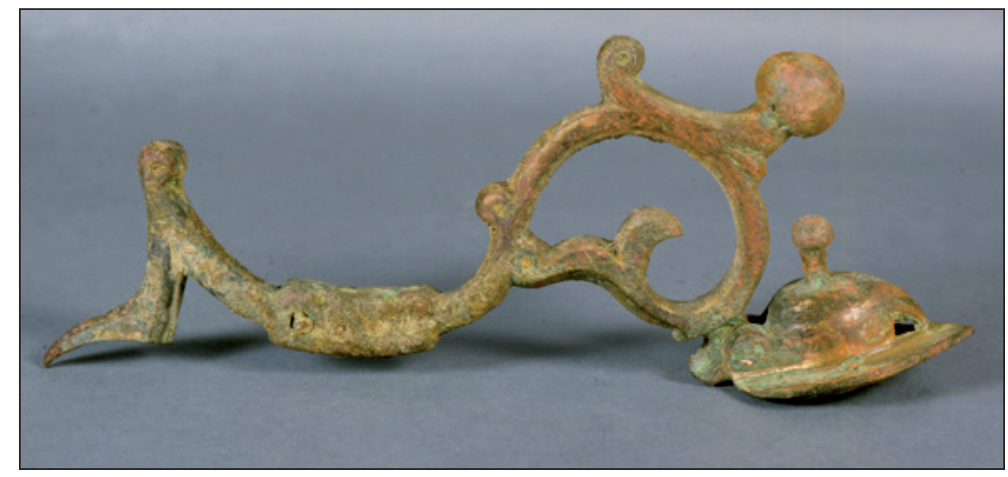

Figura 3. Asa de jarrito proveniente de Segura de la Sierra (Jaén) (Instituto Valencia de Don Juan. Archivo Fotográfico). al borde del jarro, no finaliza, sino que continúa hacia abajo en un remate floral de dos hojas divergentes, de la que la inferior queda soldada al asa a la altura del inicio de su curva superior, en la que el apéndice "aviforme" presenta un cuerpo apenas diferenciado del asa y . conserva su cabeza totalmente esférica sin botón en su parte superior. Sobre este objeto nos dice que fue

\footnotetext{
4. Término no recogido en el diccionario de la RAE, pero que utilizaremos para referirnos a los remates o adornos con forma de ave.

5. Agradecemos las facilidades y la información aportada por su directora $M^{a}$ Dolores Baena sobre este jarrito de Alcolea y sobre el hallado en el conjunto de objetos metálicos de la plazuela de Chirinos de Córdoba, así como el facilitarnos y autorizarnos la edición de las fotos.

6. Agradecemos las facilidades, información y fotografías aportadas por su directora Cristina Partearroyo.
} 
"hallado con cerámica de los siglos X-XI" (PALOL, 1950: 83, Lm. XLII-3). Su foto fue publicada sin comentario de texto alguno por L. Torres Balbás en 1957 (1987:764, f. 622).

\section{I.4. Jarrito de la Sociedad Arqueológica Luliana (fig.4)}

De procedencia insular es este jarrito hallado en la partida de "Honor/Onor" de Bunyola, en la isla de Mallorca, de la que nos dice apareció junto a un candil de bronce de doble piquera y de asa con decoración calada de tipo vegetal. Ambas piezas se conservaban en la Sociedad Arqueológica Luliana de Palma de Mallorca (PALOL, 1950: 83, Lm. XLI-3), de donde por desgracia fue robado a finales de los años sesenta y en la actualidad se desconoce su paradero? ${ }^{7}$. El jarrito desaparecido presenta unas características tipológicas muy similares a los descritos, como el cuerpo "bulbiforme" con estrías acanaladas elipsoides, cuello alto, estrecho y facetado y con anillo a modo de collar abultado. Su borde es abierto y de boca almendrada. Sin embargo, posee algunas diferencias evidentes: su base no es tan estrecha, con un perfil más sinuoso con su cuerpo, su tapadera es más de casquete esférico y, sobre todo, su asa es más estilizada, con codo menos marcado, sin decoración en su desarrollo y le falta en su hombro el característico apéndice en forma de ave, aunque se aprecia la huella de su arranque. La altura del asa no supera la de la tapadera del jarrito.

Este conjunto fue publicado posteriormente por G. Rosselló quien nos aporta la información del hallazgo producido entre los años 1940-1945 en la mencionada población y adquirido posteriormente por la Sociedad. Del jarrito nos dice que figura en la colección con el $n^{\circ}$ inv. 1428 y es de $18 \mathrm{~cm}$ de altura, comparándolo formalmente con el jarrito de Alcolea del Museo de Córdoba y con el asa del Instituto Valencia de Don Juan, sin hacer referencia bibliográfica alguna (ROSSELLÓ, 1962: 231-2, Lams. 1- 2 a 4).

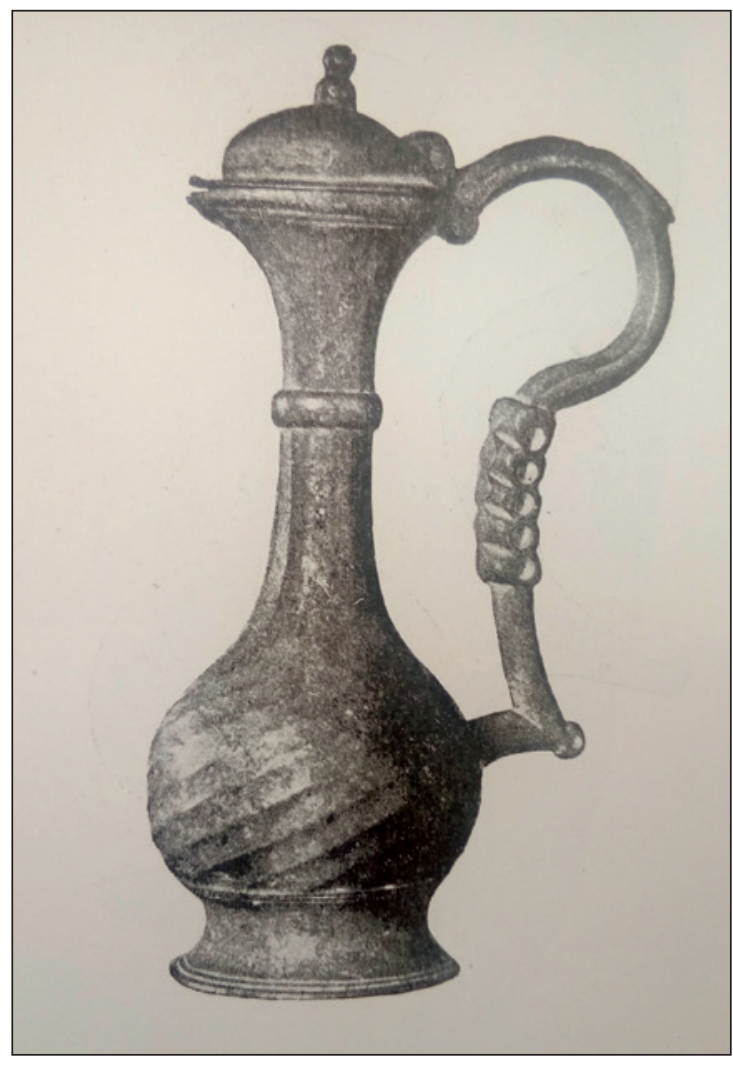

Figura 4. Jarrito desaparecido de la Sociedad Arqueológica Luliana y reproducido de la obra de Pedro de Palol (1950: 83, Lm. XLI-3).

\section{I.5. Jarrito de Valladolid}

Por último y fuera de este grupo de jarritos considerados como califales, Pedro de Palol, a sugerencia de Manuel Gómez-Moreno y de E. Camps Cazorla, hace referencia y describe un ejemplar cuya forma, al separarse de la de los hispano-visigodos, la engloba en un tipo VI, conformado por jarritos que "no son otra cosa que obras de fantasía", según sus palabras (PALOL, 1950: 80); opinión que cambiará radicalmente al conocer el ejemplar de la Plazuela de Chirinos (PALOL, 1961-1962: 708), como veremos más tarde. La pieza es la número 36 de su listado y es un jarrito de perfil piriforme, pie de copa compacto pero, a diferencia de los anteriores, su cuerpo presenta un tratamiento facetado desde la parte media del cuerpo hasta el borde de su boca con estrechamiento para

\footnotetext{
7. Información confirmada por el director del museo de Mallorca, Bertomeu Salvá Simonet y por la conservadora del mismo Rosa María Fiol, así como por el mismo Guillermo Rosselló, a los que agradezco su colaboración.
} 
facilitar el vertido de su contenido; presentando el característico anillo engrosado en el cueIlo. En la parte medial del cuerpo se conserva la marca de la soldadura del asa que falta y en el borde del jarrito, frente a su pico vertedor, se aprecia la huella del engarce del asa, la cual podría portar una posible tapadera. Se desconoce su procedencia, aunque se encontraba en el Museo Arqueológico Nacional en poder de la Junta del Tesoro Artístico Nacional con $n^{0}$ inv. 1469 hasta que fue devuelto a su propietario (PALOL, 1950: 80, Lm. XL, 2). Según el catálogo del Museo de Valladolid ingresó en el museo en el año 1941 procedente del servicio de Defensa del Patrimonio Artístico. Sus dimensiones son: altura $10,2 \mathrm{~cm}$; diám. bs. 5,3 cm y de borde 5 $\mathrm{cm}$. Su número de inventario es MAVA 9927 y está catalogado como califal de los siglos IX-XI (DELIBES; PÉREZ; WATTENBERG, 1996: 169). Se exhibió en la exposición organizada sobre El Cid, del hombre a la leyenda [Burgos, 2007] (PÉREZ, 2007:86) y posteriormente en la In principio erat verbum. El Reino de León y sus beatos [León, 2010] (GONZÁLEZ, 2010) con la misma atribución cronológica y cultural.

\section{I.6. Jarrito de la Plazuela de Chirinos de Córdoba (fig. 5)}

A escasos años de la publicación de estos jarritos (PALOL, 1950), se produjo en 1956 el extraordinario hallazgo arqueológico en la Plazuela de Chirinos de Córdoba, en el interior de su antigua medina y a unos tres metros de profundidad, de un conjunto compuesto por 13 piezas de bronce o latón que fue adquirido por el Museo Arqueológico Provincial de Córdobay dado a conocer por su director Samuel de los Santos Jener en las Memorias de los Museos Arqueológicos Provinciales (1955-7) y posteriormente en la revista Al-Mulk de Córdoba en el año 1961, aunque el texto lo había enviado en 1956 (1961-1962). En el conjunto se hallaron dos jarros de los que uno de ellos - el más pequeño- corresponde al tipo de nuestro estudio. Es la pieza número 9 del listado publicado, del que dice lo siguiente: "Jarrita de latón, fundida en forma de oinochoe. Tiene un asa en forma de ese adornada con dos esferillas. La boca es trilobulada, para verter. La decora-

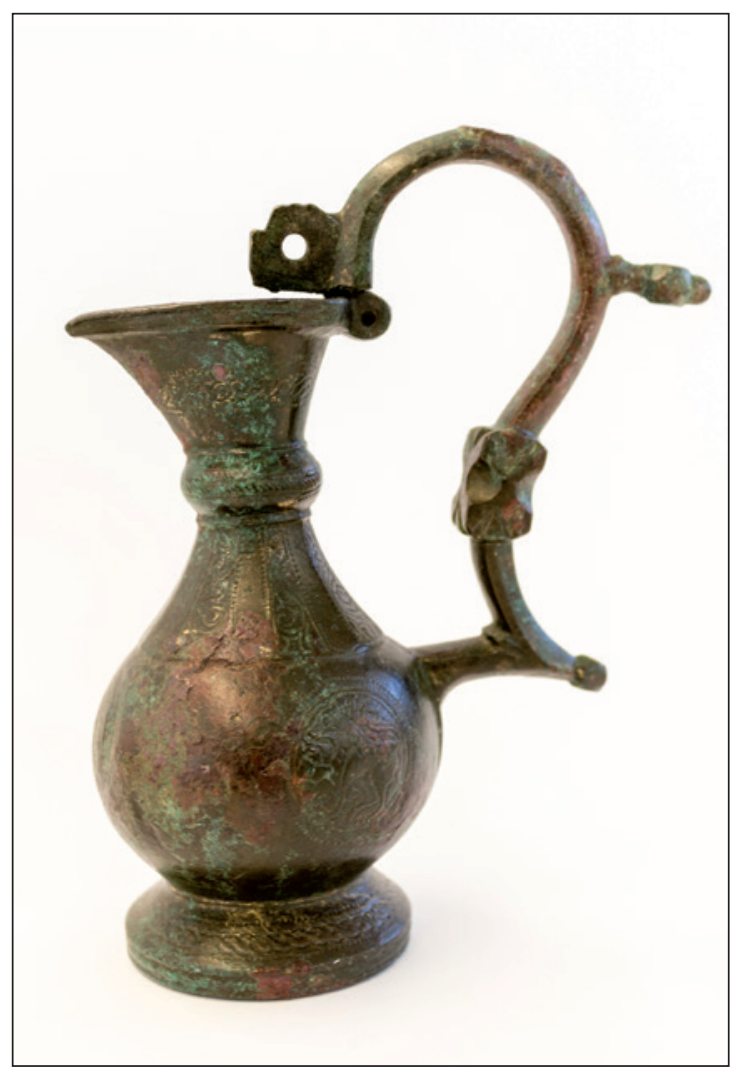

Figura 5. Jarrito de asa acodada de la Plazuela de Chirinos, Córdoba (Museo Arqueológico y Etnográfico de Córdoba. Archivo Fotográfico).

ción son fajas verticales de postas en el cuello, y medalloncitos con figuras de ciervo, leones y pavos, en la panza. Mide $154 \mathrm{~mm}$ de altura por 60 mm de diámetro" (SANTOS, 1955-7: 192193, Lm. XL).

El jarrito responde, en general, al tipo descrito, con ciertas y evidentes diferencias. En principio, su forma es piriforme, de base plana, con pie individualizado de sección troncocónica y en su cuello se desarrolla el collar moldurado. Su borde es abierto y su boca almendrada, con la diferencia de presentar un apéndice de bisagra en el lado opuesto al pico vertedor. El asa vertical, a diferencia de las piezas anteriores, arranca de la parte superior del cuerpo en recto y con codo desde donde se inicia el asa con perfil en ese. Su sección es romboidal y presenta un pequeño asidero casi cúbico con decoración de una flor tetrapétala. Continúa el asa y en el inicio de su curva se aprecia, a 
diferencia de los otros jarritos, un apéndice horizontal de cuerpo facetado y remate de botón. Termina el asa con la lengüeta transversal perforada por la charnela para la tapa que no se conserva (PALOL, 1961-1962, n 9, f. 4). Por último y de forma similar al anterior, su cuerpo es facetado y no presenta una decoración con acanaladuras elipsoides. Además y de manera excepcional, su cuerpo está decorado con tondos incisos rellenos con motivos zoomorfos.

Según consta en la ficha del catálogo CERES.mcu.es, la pieza tiene el número de inventario D0000092/9 y sus dimensiones son las siguientes: altura $15,5 \mathrm{~cm}$, diám. bs. $5,5 \mathrm{~cm}$ y de la boca 3,5 cm. (http://ceres.mcu.es/pages $/$ Viewer?accion=4\&AMuseo=MAECO\&Nin$\mathrm{v}=\mathrm{D} 0000092 / 9$ )

El jarrito en su publicación y desde un primer momento fue considerado como de época califal y procedente de un taller cordobés (SANTOS, 1955-57; 1961-2). Fue publicado por Leopoldo Torres Balbás considerando al jarrito como de azófar, de época califal y de influencia iraní (TORRES, 1987: 762, f. 619). Pocos años

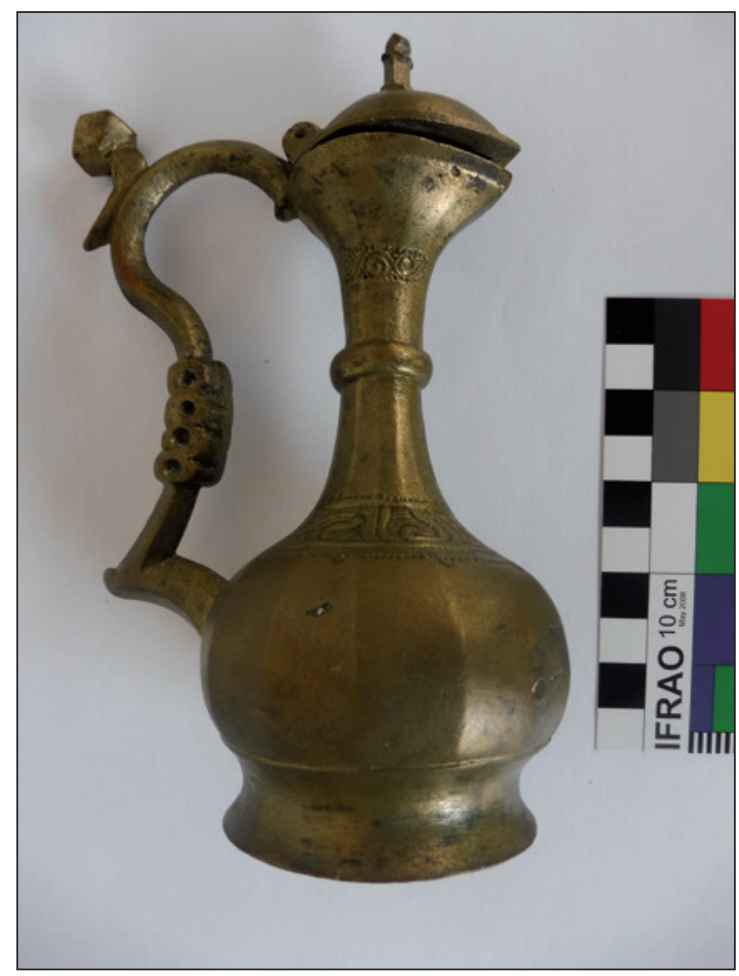

Figura 6. Jarrito de la C/Cortés de Murcia (Museo Santa Clara de Murcia. Foto del autor). después, el mismo Pedro de Palol en un artículo de revisión de los bronces litúrgicos hispano-visigodos recogía la noticia de la aparición del conjunto de la Plazuela de Chirinos y describía y analizaba este jarrito sugiriendo su parecido perfil al jarrito número 36 de su listado y depositado en el Museo Arqueológico de Valladolid (PALOL, 1950: 80, Lm.: XL, 2) y mantenía sus precedentes coptos aunque recogiendo la propuesta del origen iraní lanzada por L. Torres Balbás (PALOL, 1961-2: 708). Por último, tras el estudio epigráfico del conjunto realizado por M. Ocaña, no cabe duda de que la pieza es contextualmente de finales del s. XII, primer cuarto del siglo XIII (OCAÑA, 1985:405), como hemos confirmado en nuestra reciente investigación (AZUAR, 2019a).

\section{I.7. Jarrito de la C/ Cortés de Murcia (fig. 6)}

Apareció en las excavaciones llevadas a cabo en 1991 en los solares de los números 13, 15, 17 y 21 de la calle Cortés del barrio intramuros de San Nicolás de Murcia, aunque no se hace referencia alguna del hallazgo en los trabajos publicados de la mencionada excavación (MUÑOZ, NAVARRO, 1994; MUÑOZ, 1994, 1999), como ponemos de relieve en nuestro estudio monográfico (AZUAR, 2019).

El jarrito se conserva completo y es de base plana, su cuerpo es de perfil piriforme y su cuello es estrecho, alto, con moldura anular en su parte media, que se abre para formar su borde almendrado hacia la izquierda para facilitar el vertido. Remata el jarro una tapadera de base almendrada y forma semi-ovoide horizontal. El jarrito posee un asa en su lado derecho, siguiendo la orientación de la inscripción, que en su tramo medial se localiza un asidero de tipo prismático vertical de sección rectangular y se remata en la parte alta de su curva con un apéndice en forma de "ave", con cabeza romboédrica de planos romboidales

Como decoración presenta, al igual que los ejemplares 5 y 6 de nuestro listado, un tratamiento facetado ligeramente sugerido en el cuerpo y parte inferior del cuello. Como singu- 
laridad y a la altura del engarce del cuerpo con el cuello se desarrolla una cartela epigráfica horizontal enmarcada entre líneas horizontales de puntos. Remata decorativamente la pieza una cartela emplazada en la parte superior del cuello, de motivo de ataurique o vegetal inciso. Sus dimensiones son: $15 \mathrm{~cm}$ de altura, $5,3 \mathrm{~cm}$ de diám. bs. y un máximo de cuerpo de $6,4 \mathrm{~cm}$. Se conserva en el Museo de Santa Clara de Murcia ${ }^{8}$ con número de inventario MSCL/ CE070140, aunque en origen disponía de la signatura MC48.

El ejemplar se exhibió por primera vez en la exposición Regnum Murciae. Génesis y configuración del Reino de Murcia (2008), su ficha de catalogación fue realizada por Alfonso Robles y el estudio epigráfico estuvo a cargo de la especialista M ${ }^{a}$ Antonia Martínez Núñez, de la Universidad de Málaga, que tradujo la frase: La felicidad y la gloria perpetua, así como por sus rasgos epigráficos proponía el que fuera una pieza de cronología hûdí o incluso mudéjar (MARTíNEZ, ROBLES, 2008: 377). En nuestra reciente investigación, coincidimos en su cronología arqueológica y epigráfica, aunque sugerimos que puede ser una pieza ayubí, de un taller iraní, e importada a través de Egipto aprovechando las buenas relaciones existentes entre los hudíes y los hafsíes de Túnez (AZUAR, 2019).

\section{EL DEBATE HISTORIOGRÁFICO: JARRITOS COPTOS, FATIMÍES O DEL MEDIO ORIENTE}

Es evidente que cuando la directora del Museo Arqueológico Provincial de Granada, Joaquina Eguaras inscribe y publicita la donación de D. Manuel Gómez-Moreno de diversas piezas de su colección privada, al catalogarla e identificar el jarrito recogido en este estudio se limitó a transcribir la adscripción cultural e histórica de época visigoda dada por su dueño. Convencimiento constatado al comprobar que Manuel Gómez-Moreno no incluyó a estos jarritos entre los objetos de bronce de su estudio del Arte Califal del volumen III del Ars Hispaniae, editado en 1951.

Como se ha visto, el primero que considera a estos jarritos como islámicos fue precisamente Pedro de Palol quién llega a esta conclusión tras analizar y estudiar los jarritos hispano-visigodos conocidos en ese momento en la Península y en el Mediterráneo y, ante las evidentes diferencias formales, consideró oportuno el incluirlos en un subcapítulo que, como ya vimos, se intitulaba "Jarritos califales de origen copto", siguiendo sus palabras (PALOL, 1950:83):

"No es difícil precisar el origen copto de estos bronces. La forma del asa, con una porción superior circulary la inferior recta segmentada, uniendo en codo al jarro, así como la ornamentación del cuerpo con surcos, son características de los bronces egipcios".

La atribución de tradición copta de estas piezas se basaba en la forma en codo del asa y en el desarrollo facetado del cuerpo; como prueba hacía referencia a un jarrito procedente de un monasterio copto, adquirido en 1894 por el Museo Británico de Londres, también de similar altura $15 \mathrm{~cm}$, con una cabeza de caballo en el asa y del que aportaba una fotografía (PALOL, 1950:83, Lm. XLI, 1). Este jarrito fue publicado por O.M. Dalton en el catálogo de Antigüedades Cristianas del Museo Británico, incluido entre los objetos variados de cronología posterior al siglo VI d.C. (1901: 107, n 539). Tipo de jarrito que, sin embargo, no aparecía recogido entre los perfumeros o esencieros del catálogo de objetos coptos del Museo de El Cairo debido a Josef von Strzygowski (1904:276-8, taf. XXX).

Pedro de Palol para reforzar su hipótesis de precedentes coptos aportaba además la referencia de otro ejemplar aparecido en unas obras en la "Via Cavour" de Siracusa (Sicilia) (PALOL, 1950: 83, Lm. XLI, 2), publicado por Paolo Orsi en

8. Agradecemos las facilidades debidas a la directora del museo Mª Ángeles Gómez Rodenas, para la documentación gráfica y fotográfica. 
1912 (1942: 181, Tav. XII,b) $)^{9}$ quien lo consideraba por el contrario como de origen o tradición bizantina y dentro del mundo de los objetos litúrgicos de uso cristiano, por su similitud con las redomas de cristal de los siglos VI-VII, citando como paralelo, igualmente, el mencionado jarrito del Museo Británico (ORSI, 1942: 180, Lm. XII, b). Aunque los paralelos presentados eran jarritos con tapadera considerados como cristianos, ya sean bizantinos o coptos, Pedro de Palol no dudó en clasificar a los conocidos de la Península como califales por sus evidentes diferencias formales respecto a los hispano-visigodos. Más aún, manifestaba que "no creemos aventurado, sin embargo, pensar que, en la serie cronológica de los jarros califales, el siciliano sería el más moderno derivado, precisamente, de talleres andaluces" (PALOL, 1950:84).

Estos jarritos fueron publicados por Leopoldo Torres Balbás pero -a diferencia de la opinión de Pedro de Palol- los consideró como de precedentes iranios, aportando el ejemplo del jarrito completo conservado en la Brummer Gallery de Nueva York, catalogado por Richard Ettinghausen como abasí de los siglos VIII O IX y exhibido en la exposición Metalwork from islamic countries (1943) (TORRES, 1987: 762, nota 51, F. 620) (f. 7).

El mencionado jarrito, y según consta en su ficha del Metropolitan Museum of Art de Nueva York, fue adquirido en Irán. Su número de inventario es el 49.49 y sus dimensiones son 24,8 $\mathrm{cm}$ de altura y $11,9 \mathrm{~cm}$ de diámetro de base. Es del tipo piriforme, base plana con tres pequeñas patitas de botón, cuerpo globular con marcada moldura en el cuello y borde almendrado. Su asa es más estilizada, en codo con perforaciones, asidero cúbico y perforado en retícula, apéndice transversal en el hombro del asa y en su parte superior otro vertical con remate de cabeza cúbica de planos romboidales. El asa con la charnela de la tapa se funde con el borde del jarrito. La decoración de su cuerpo es de ligeros e insinuados gallones verticales que ascienden hasta el borde. Se exhibió en

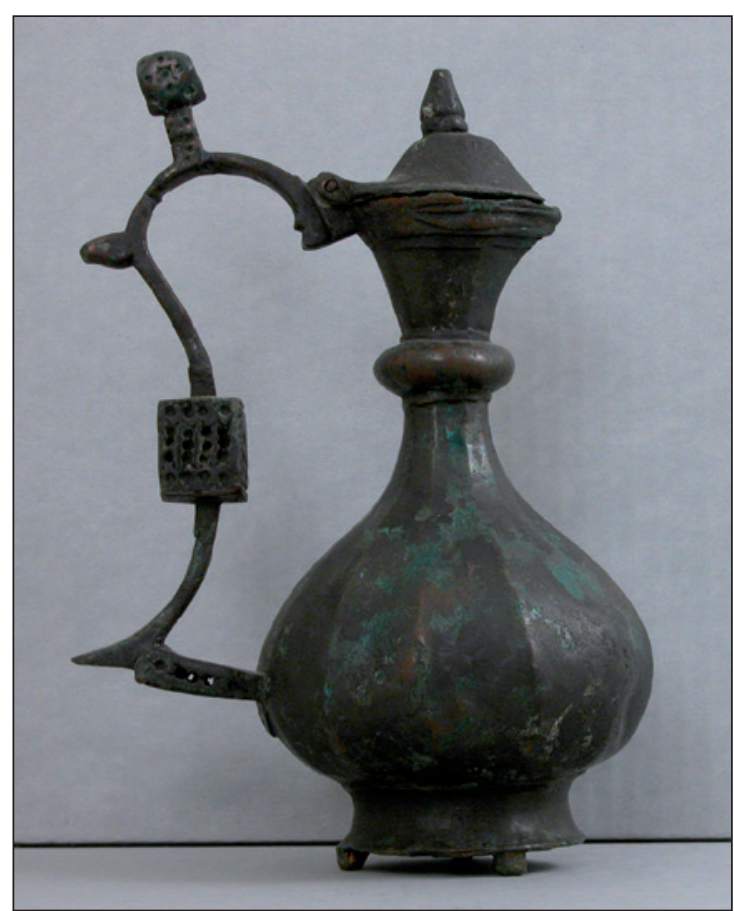

Figura 7. Jarrito de la colección Brummer (Museo Metropolitano de Arte de Nueva York).

Berlín en la exposición The Arts of Islam (ETTINGHAUSEN, 1981: 44-5, n 9 ) y se ha publicado en la obra de Wigdan Ali, The Arab contribution to Islamic Art: from the Seventh to the Fifteenth Centuries, donde se ratifica su primera clasificación, considerándolo como Omeya o preabasí de los siglos VIII-IX (1999: 44-45, f. 18).

Inexplicablemente y hasta ahora, ningún investigador peninsular ha mostrado interés por estos jarritos. Así, el mismo Juan Zozaya, quien más ha trabajado sobre los objetos metálicos andalusíes, en su ponencia en el IV Congreso de Arqueología Medieval Española (1993) sobre "Importaciones casuales en al-Andalus: las vías de comercio", al hablar sobre los bronces conocidos en general y partiendo del estudio de los jarritos litúrgicos de Pedro de Palol, se decanta por centrarse en el análisis específico del jarrito de tipo "gutiforme", sin interesarse por el grupo formal que nos compete (ZOZAYA, 1993:125, f. 7 , d y f), del que, precisamente en su posterior artículo "Aeraria de Transición: objetos con base de

\footnotetext{
9. Agradezco a Patrice Cressier el que me haya facilitado una copia de la mencionada publicación a través de Elena Pezzini, conservadora en el Museo Archologico Regionale "Antonio Salinas" de Palermo.
} 
cobre de los siglos VII al IX en al-Andalus", viene a decir lo siguiente (2010:20-21).

"Otra serie que plantea problemas es la de los denominados jarritos de bronce, que fueron estudiados, en su día, por Palol (1950), que prácticamente consideró como hispanos a todos los encontrados en la Península. Sin embargo, aquellos, que él describía como los más raros y tardíos, [es decir los del tipo VI], se ha demostrado que son fatimíes del siglo $\mathrm{X}$, tanto por los hallazgos orientales como por los encontrados en diversos museos con procedencias más o menos fiables. Por lo tanto, este lote ha de ser descartado ya de su elenco [andalusí]"

Ciertamente, en el ámbito internacional este tipo de jarritos, de forma general, sí que han merecido la atención de los investigadores. Así, tenemos que retrotraernos al Manuel d'Art Musulman. Arts Plastiques et Industrials escrito por el director honorario de los Museos Nacionales de Francia, Gaston Migeon, quien en el segundo volumen de la obra y en el capítulo dedicado a los "cobres" y a su metalurgia de origen sasánida iraní trae a colación -entre otras piezas de la colección Harari de El Cairo- un ejemplar de jarrito piriforme con tapadera, de cuerpo gallonado, anillo del cuello con decora-

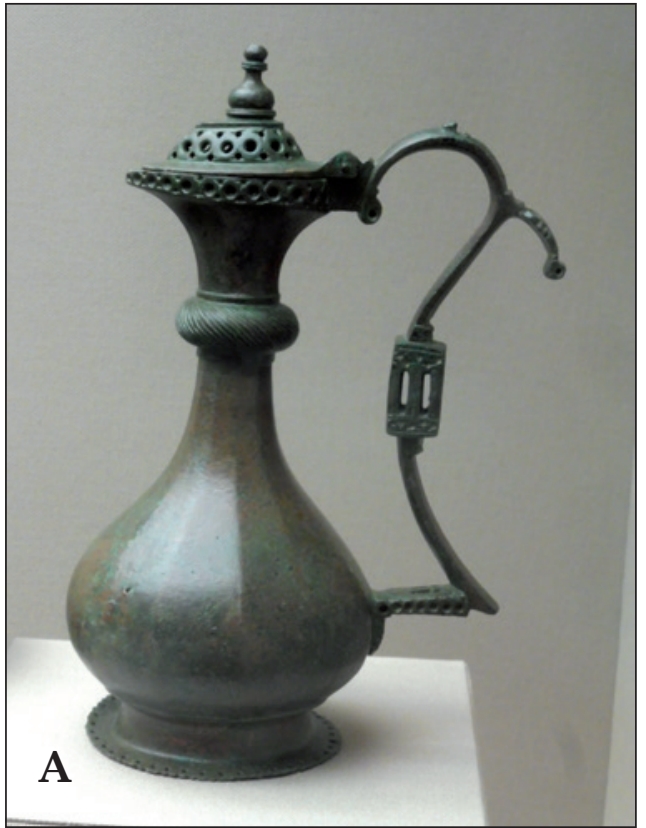

Figura 8. (A y B) Jarritos expuestos en el Museo de Arte Islámico de la fundación Benaki. Atenas (El B es el número 13129).

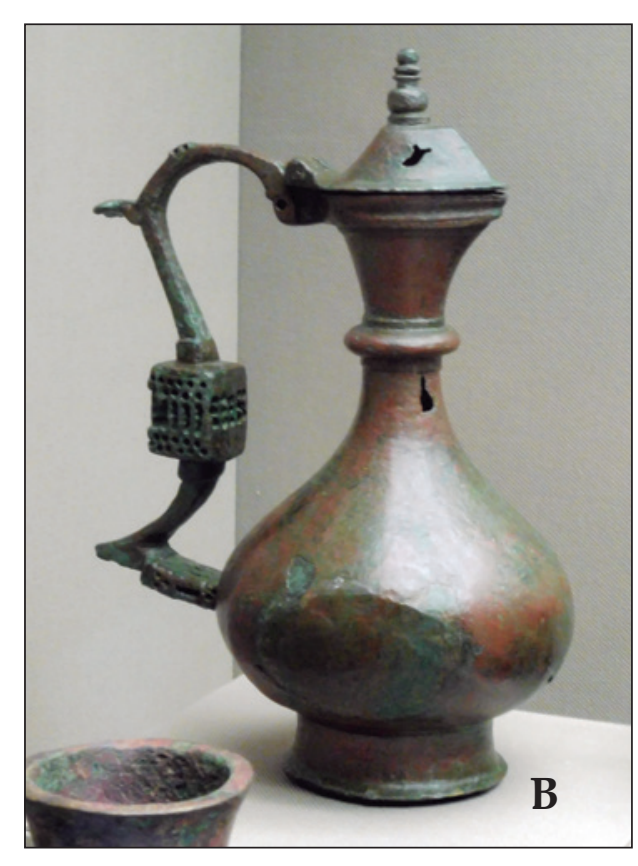

ción incisa helicoidal y con la particularidad de presentar en su asa acodada, como remate en su parte superior, la figura de un león sentado. Jarrito al que consideró como "proto-islámico" o de la primera época del islam y de tradición del arte persa o iraní (MIGEON, 1927: II, 29-30, f. 227). Hipótesis de precedentes iraníes para este tipo de jarritos que será recogida, posteriormente y como se ha visto, por Richard Ettinghausen al defender el origen Omeya o pre-abasí dado al mencionado jarrito adquirido a principios del siglo en Irán y perteneciente a la colección Brummer (1943). Atribución del Irán abasí de este jarrito que será la defendida por L. Torres Balbás para el ejemplar hallado en el conjunto de la plazuela de Chirinos de Córdoba (1987: 762, nota 51, f. 620).

Sin embargo, la novedosa hipótesis iraní como precedente de este raro ejemplar de jarrito con tapadera -del que apenas en la primera mitad del siglo XX solo se conocían los tres ejemplares mencionados- seguía compitiendo con la atribución tradicional de su origen copto, siguiendo la primigenia clasificación del Museo Británico (DALTON, 1901) y presente en el fundamental catálogo de objetos de metal islámico de la Keir Collection que realizara Géza Fehérvári, quién en el capítulo segundo 
- dedicado a los metales en Egipto, Sicilia y España de los siglos VII al XII- presentó un jarrito con tapadera, adquirido en Egipto en 1967, del tipo piriforme de cuerpo gallonado, al que le falta la tapadera y en su asa presenta como apéndice la cabeza de un caballo o de otro mamífero, y al que consideró como egipcio de los siglos VII-IX, aunque de evidente tradición copta y añadiendo su carácter mediterráneo por su ámbito de aparición (FEHÉRVÁRI, 1976: 46, n² 21, f. 7b). Como paralelo a esta pieza señala solo el mencionado jarrito del Museo Británico, sin hacer mención alguna a los ya descubiertos y publicados de la Península por Pedro de Palol (1950) y por L. Torres Balbás (1957), obras que, inexplicablemente no aparecen en su bibliografía de referencia.

Desconocimiento absoluto de los jarritos andalusíes que se constata en la obra posterior de Eva Baer: Metalwork in Medieval Islamic Art, en la que en el capítulo dedicado a los Ewers and Pitchars, trae el ejemplo de un nuevo jarrito con tapadera, uno de los dos existentes en el Museo Benaki de Atenas, con número de inventario 13129, bastante deteriorado en la parte central de su cuerpo, de tipo piriforme, con tapadera y por suerte totalmente restaurado en la actualidad, del que dice está considerado como egipcio de primera época islámica (BAER, 1983: 84, f. 64) (fig. 8B). En su nota nº 194 aporta como paralelos a este nuevo ejemplar los jarritos mencionados del Metropolitan Museum of Arts de Nueva York, el del British Museum, el de la colección Harari de El Cairo, con $n^{\circ}$ 15266, y da la noticia de un nuevo ejemplar, de la colección Kelekian, que salió a subasta en 1975 y del que se desconoce su paradero, aunque podría ser -según nuestra opinión- el otro ejemplar de jarro expuesto en la actualidad en las salas del Museo de Arte Islámico de la fundación Benaki en Atenas ( $n^{0}$ inv. 13130) (fig. 8A). Sorprendentemente y de nuevo, otro investigador que no hace mención alguna a los ejemplares de jarritos peninsulares ni a los trabajos de referencia de la investigación española. Una prueba más de que estamos en el lado oculto de la historiografía internacional.

Tendremos que esperar a la aparición de los estudios de James W. Allan, -especialista y doctorado en bronces islámicos iraníes (1976, 1979) y autor de la publicación de los bronces de las excavaciones de Nishapur (ALLAN, 1982)- sobre el conjunto de bronces islámicos de la colección Aron (ALLAN, 1986: 16-7,f. 3), en cuya introducción hacía mención a estos jarritos con tapadera y recogía por primera vez los ejemplares andalusíes, aunque no sabemos en qué se basaba para considerar al jarrito de la colección Keir, publicado por G. Fehérvári, como de procedencia libanesa (ALLAN, 1986: 16 , nota $\left.n^{0} 8\right)$. Su conocimiento de las colecciones metálicas persas e iraníes le permitió confirmar que este tipo de jarritos no se encuentra entre los bronces iraníes estudiados por A. S. Melikian-Chirvani (1973; 1976), ni en su documentada obra: Islamic Metalwork from the Iranian World. 8-18th centuries (1982).

A la constatación de esta ausencia entre los registros iraníes, J. Allan añadiría la distribución geográfica de aparición de estos jarritos, lo que le llevó a sugerir la existencia de un mercado o espacio mediterráneo para estos objetos, defendiendo la antigua y tradicional atribución copta de estos jarritos y sugiriendo su procedencia del área de Alejandría, aunque de una cronología posterior islámica y pre-fatimí de los siglos VIII-X basada en la presencia de zoomorfos en su decoración, de claros precedentes en el famoso jarro o botella omeya de Marwân de los siglos VIII-IX (ALLAN, 1986: 17). Tesis defendida posteriormente por R. Ward en su obra Islamic Metalwork, en la que pone de relieve los evidentes precedentes coptos de los metales fatimíes, haciendo expresa mención de los jarritos andalusíes y presentando de nuevo el jarrito procedente de un monasterio de Egipto y conservado en el Museo Británico, aunque actualizando su cronología, al considerarlo con toda probabilidad como egipcio de los siglos IX a XI (WARD, 1993: 64, f. 47).

A pesar de la ausencia de este tipo de jarritos en los registros iraníes, confirmada en la reciente revisión efectuada por Valentina Laviola sobre: Metalli islamici dai territori Iranici orientali (IX - XIII sec.) (2016) y del reconocimiento generalizado de la procedencia fatimí de estos jarritos, todavía seguimos asistiendo 
a la datación sasánida iraní de este tipo de piezas, como sucede con el jarrito conservado en el Museum für Islamische Kunst de Berlín, con número I.2071, al que le falta la tapadera y está muy deteriorado, pues no conserva los remates del asa, y a pesar de la información y documentación conocida, está considerado como sasánida, de procedencia iraní y de los siglos V-VI d.C., según su catálogo digital (http://www.smb-digital.de/eMuseumPlus?service=Externallnterface\&lang=en). Lo mismo sucede con el asa de jarrito que se conserva en la Bumiller-Collection de Bamberg (Alemania), con $\mathrm{n}^{0}$ inv. $\mathrm{BC}-131$, que presenta como rasgo distintivo en la parte superior del asa una figura, de difícil identificación, que podría ser un ave o un zoomorfo, también considerada como iraní (DAHNCKE, 1997: 192-193, Abb.50c).

De igual forma -pero al contrario- sorprende el consultar la monografía y detallado estudio doctoral de Kirsten Werz sobre los bronces coptos Sogenanntes koptisches. Buntmetallgeschirr donde incluye este tipo de jarritos en el grupo 2 de su clasificación y en el que a los jarritos de procedencia andalusí de la antigua lista de P. de Palol (1950), los considera como una producción propia peninsular pero de tradición romana, poniendo en duda su origen islámico (WERZ, 2005: 24-25; taf. 3).

\section{LOS JARRITOS DE AL-ANDALUS EN EL CONTEXTO MEDITERRÁNEO SEGÚN SU TIPOLOGÍAY DECORACIÓN}

Desde el mero análisis formal y decorativo, coincidimos con K. Werz en agrupar al conjunto de objetos conocidos y recogidos en este estudio -que superan la cifra de una docena de piezas, muy superior a los siete ejemplares de su investigación- dentro de su grupo "2" de los jarritos (Kannenform 2), caracterizados por su cuerpo piriforme con tapadera, el presentar su característico anillo engrosado en el cuello y su asa acodada con apéndice para apoyar el dedo (WERZ, 2005: 26 y79). Dentro de este tipo general, establece los dos subgrupos formales siguientes:
El subtipo "A", en el que solo incluye un ejemplar, precisamente el jarrito del Museo Británico al que considera como cristiano copto del siglo VI d.C., que se caracteriza por su base plana, perfil piriforme y presentar una característica decoración facetada desde su cuerpo hasta el cuello, en donde es notoria la presencia de su anillo o collar abultado. Otro factor identificador del tipo es el que en el asa suele aparecer o rematarse con un apéndice zoomorfo.

A este grupo, aparte del mencionado ejemplar, habría que añadir, por sus rasgos formales, los ejemplares siguientes ya descritos: nos referimos al jarrito de la colección Brummer, a los dos de procedencia egipcia conservados en el Museo de Arte Islámico de la fundación Benaki de Atenas, al de la colección Harari del Museo de El Cairo y al de la Keir collection de Londres. Este grupo tipológico se completaría con los ejemplares hallados en la Península, nos referimos en principio al extraño jarrito $n^{\circ}$ 36 del listado de P. de Palol (1950: 80), al aparecido posteriormente en la plazuela de Chirinos de Córdoba (SANTOS, 1955-7, 1961) y el más reciente hallado en la calle Cortés de Murcia (MARTÍNEZ, ROBLES, 2008: 377; AZUAR, 2019).

En total un primer conjunto formado hasta el momento por nueve ejemplares de los cuales los ocho últimos, como se ha visto, no serían cristianos sino islámicos y de cronología posterior a la propuesta por K. Werz en su estudio.

Entre los ejemplares de este subtipo "A", además se distingue un conjunto caracterizado por la presencia de un "zoomorfo" en el apéndice medial del asa. Como sucede en el jarrito del Museo Británico, con la cabeza de un caballo o gacela orientada al exterior. También en disposición y motivo similar es el que encontramos en el jarrito de la Keir Collection. Por último, el ejemplar de la colección Harari del Museo de El Cairo, en el que se identifica un león erguido y orientado hacia la boca del jarrito. A estos ejemplares, añadiríamos el asa de la colección Bumiller (Berlín) en la que se distingue en su parte superior un apéndice con forma de zoomorfo, ausente en los ejemplares del Museo de Arte Islámico de la fundación Benaki, muy posible- 
mente por rotura previa a su adquisición. Jarritos que -por la presencia de estos "zoomorfos" en el asa- J. W. Allan los consideraba fatimíes de los siglos X-XI y procedentes de un posible taller ubicado en Alejandría.

Por contra, los jarritos de este subtipo "A" hallados en la Península no presentan en sus asas estos "zoomorfos" y, además, son decorativamente diferentes. Así, el jarrito de la Plazuela de Chirinos de Córdoba sorprende por su rica decoración incisa: con motivos de zoomorfos que decoran en su totalidad la parte central de su cuerpo y sus gallones rellenos de cenefas verticales con motivos vegetales, cerrando la composición la presencia de sogueados en el pie de su base, en el anillo y en la parte media del cuello. Por otro lado, el ejemplar hallado en Murcia no presenta este tipo de decoración pero, sin embargo, es el único de los jarritos con tapadera de nuestro estudio que porta en el arranque del cuello una cenefa epigráfica. En conjunto, ejemplares de jarritos que -decorativamente- no responden a los rasgos generales de este subtipo "A".

A la vista de sus rasgos tipológicos y decorativos, se puede concluir que el grupo de jarritos del subtipo "A" o de perfil piriforme con cuerpo facetado, podría considerarse, por la geografía de sus hallazgos, como del Mediterráneo Oriental, de una cronología de los siglos X-XI y por tanto fatimíes de tradición copta. Así también, dentro de este subtipo se identifica claramente un subgrupo dominante formado por aquellos jarritos que portan en el asa figuritas de "zoomorfos" que podrían proceder de un mismo taller, quizás de la zona de Alejandría, como sugería James W. Allan (1986:17).

El subtipo "B" -el más numeroso en el estudio de K. Werz (2005:79) - agrupa, precisamente, a los ejemplares de jarritos hallados o procedentes de al-Andalus que publicara en su día Pedro de Palol (1950). A estos añade en su catálogo el número 2 que, dice, corresponde a un jarrito procedente de Cerdeña y depositado en el Museo de Cagliari -según una publicación de Martín Almagro Gorbea (1966: 376, f. 2)- que desde luego no corresponde, ni de lejos, a esta forma, sino más bien al tipo de jarritos importados de estilo italo-bizantino (PALOL, 1950: 64-6). Por último, a este grupo formal habría que añadir, según nuestra opinión, el jarrito conservado en el Museum für Islamische Kunst de Berlín, con número I.2071, al que le falta la tapadera.

Se caracterizan los ejemplares de este subtipo "B" por su base plana, cuerpo "bulbiforme", con cuello estilizado y con la presencia de su anillo o collar. A diferencia del grupo anterior, en su cuerpo se desarrolla una decoración en relieve de trazado helicoidal, posiblemente hecha a cuerda en el molde de cera. Otro elemento, que se repite en las piezas del grupo, es la existencia en la parte superior del asa de un apoyo con forma que sugiere un "ave" dispuesta hacia el jarro, con la característica cabeza esférica y un botón en su parte alta que encontramos en el jarrito de Alcolea de Córdoba, en el depositado en el museo de Granada, así como en el asa de Segura de la Sierra de Jaén -conservada en el Instituto Valencia de Don Juan-y es patente su presencia en el ejemplar de jarrito hallado en Siracusa (Sicilia), aunque apenas se sugiere en el jarrito del Museo de Arte Islámico de Berlín. Además y de forma general, estos jarritos son de menor tamaño que los del subtipo "A", lo que sugiere una evidente diferencia funcional y por tanto se pueden considerar estos jarritos como "vinajeras o aceiteras".

Es evidente que estos jarritos del subtipo " $\mathrm{B}$ " son muy diferentes formal y decorativamente de los del subtipo "A". De igual forma, la geografía de aparición de los jarritos es totalmente distinta, no proceden de lugares del oriente mediterráneo sino del Mediterráneo Occidental, en su mayoría del territorio de al-Andalus, incluyendo Mallorca, con un ejemplar en Siracusa (Sicilia). Estas diferencias y rasgos propios del grupo tipológico permiten asegurar que, en contra de la opinión de R. Ward (1993: 64), estamos ante piezas no importadas, sino que corresponden a una producción eminentemente andalusí y de una cronología post-califal como veremos a continuación. 


\section{ARQUEOLOGÍA CONTEXTUAL Y DATACIÓN DE LOS JARRITOS DE AL- ANDALUS}

Hasta el momento y a la vista de la historiografía nacional e internacional sobre estos jarritos, su identificación cultural y cronológica se ha basado en el análisis a partir de sus rasgos decorativos y artísticos, de sus precedentes y paralelos formales, ya que todas las piezas conocidas y depositadas en los museos provienen, como se ha visto, del mercado de antigüedades y del ámbito del coleccionismo privado y de las subastas.

Para evitar las diferencias historiográficas analizadas, así como para poder contrastar las diversas hipótesis sobre la identificación cultural y cronológica de estos jarritos, nos parece necesario recurrir a la información arqueológica que disponemos de los mismos en la actualidad.

Por suerte, para conocer el amplio y variado registro de objetos metálicos de época fatimí disponemos de la publicación del excepcional hallazgo del conjunto de bronces aparecido en las excavaciones de la ciudad islámica -bajo dominio fatimí- de Tiberiades (Israel) (HIRSCHFELD, UTFELD, 2008) y debida a E. Khamis autor de la monografía: The Fatimid metalwork hoard from Tiberias. Tiberias: excavations in the house of the bronzes (2013). En este extenso volumen en el que ha catalogado e identificado más de medio millar de objetos - procedentes de tres grandes tinajas enterradas en el suelo, de lo que parece una factoría- se documenta cómo en el interior de las vasijas que contenían los bronces aparecieron también un centenar de folles bizantinos de una cronología del siglo X al 1067. A esta cronología contextual hay que añadir la datación arqueológica del yacimiento, amortizado tras su conquista y saqueo llevado a cabo por los cruzados en el 1099 (KHAMIS, AMIR, 1999), lo que refuerza la cronología del último tercio del siglo XI para este conjunto de bronces procedentes de una fundición de época fatimí.

En el documentado catálogo, entre los jarritos inventariados encontramos los ejemplares

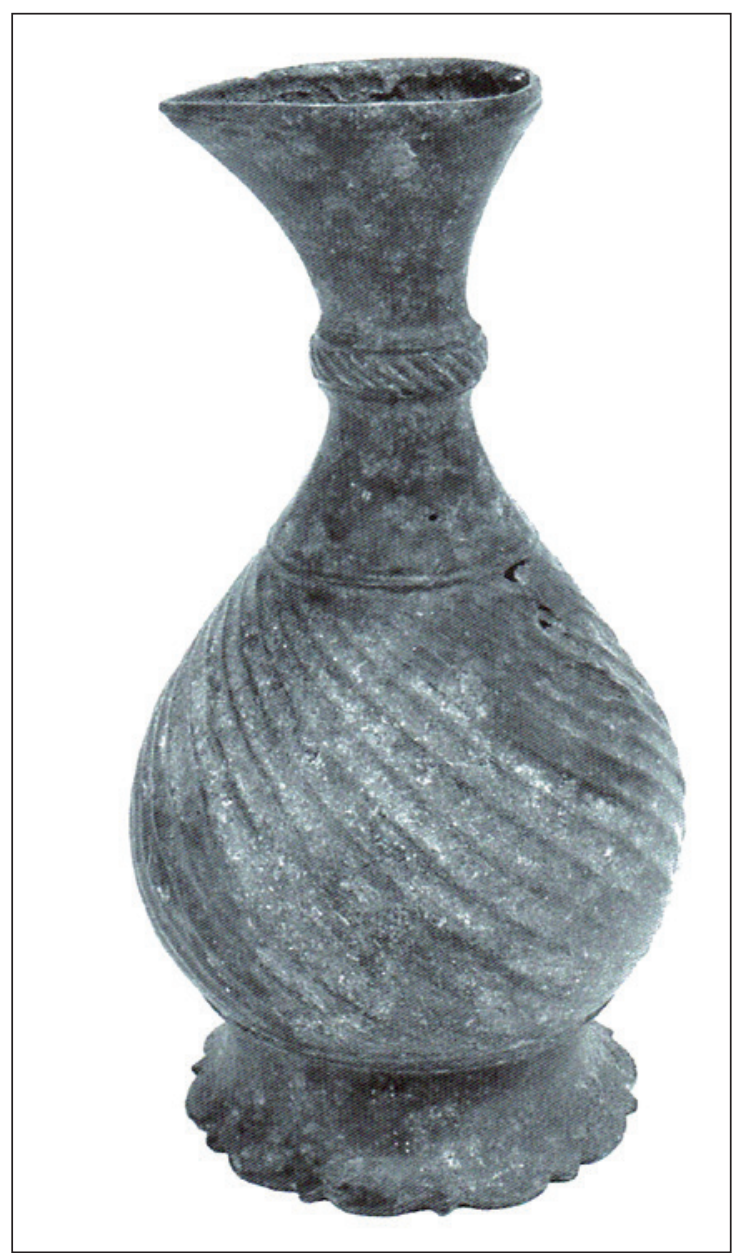

Figura 9. Reproducción del Jarrito $n^{\circ} 191$ del conjunto de Tiberiades (Cortesía de E. Khamis, 2013: 162).

n 191 y 192 (KHAMIS, 2013: 158-159), de base plana, cuerpo piriforme, anillo engrosado en el cuello y boca almendrada con pico vertedor, siendo sus alturas de $17 \mathrm{~cm}$ y de $13,7 \mathrm{~cm}$ respectivamente y a los dos les falta el asa. De estos, el no 191 es muy interesante porque presenta una decoración con incisiones elipsoides en el cuerpo y en su collar y se le asocia al asa $n^{\circ} 217$ (KHAMIS, 2013: 162), que se caracteriza por su arranque ligeramente acodado, desarrollo en "S", con asidero en su tramo medio de tipo prismático y perforado, rematándose la parte superior del asa con su característica e identificadora ave o paloma mirando hacia la boca del jarro. Se remata el asa, en su extremo final con una boca abierta preparada para engarzarse al borde del jarro. Ejemplar similar, aunque algo menos elaborado y más esque- 
mático es el asa n² 218, (KHAMIS, 2013:162), también con remate "aviforme".

Estos dos ejemplares los incluye en el tipo "A" de su clasificación de los jarritos - denominados Jugs with piriform body, narrow neck and almond-shaped mouth- a los que vincula formalmente con los ejemplares conocidos internacionalmente -ya mencionados-y con los andalusíes publicados por Pedro de Palol, sin recoger los hallazgos posteriores (KHAMIS, 2013: 55-57).

Su revisión lo lleva a plantear la hipótesis de que los ejemplares hallados en Tiberiades, por su forma y decoración incisa elipsoide, están inspirados directamente en los jarritos de cristal o de "cristal de roca" fatimíes (KHAMIS, 2013: 75), poniendo como paralelo su evidente parecido formal con el jarrito de vidrio que se conserva en el Museo Islámico de Berlín, de procedencia egipcia y de los siglos VIII-X (BRISCH, et alii, 1986:60, n²48). Hipótesis difícil de mantener a la vista del amplio registro de tipos y formas de vidrio de época fatimí hallados en el pecio del Serçe Limani (Turquía), datado en el primer tercio del siglo XI (BASS, et alii, 2003), y recogidos en el documentado segundo volumen, en cuyos capítulos dedicados a los jarritos o Ewers y a los jarros o Jugs, no aparece ninguna forma del tipo piriforme, solo los esencieros o vinajeras que son de forma cónica, con base plana y asa recta vertical. Por otro lado, los jarros o Jugs, son de pie anular, cuerpo globular y cuello estrecho y alto, con asa recta vertical (BASS, et alii, 2009: 293-308) y en ninguno de estos jarritos ni en el resto de los ejemplares del cargamento aparecen vidrios con decoración de desarrollo elipsoide.

Más realista, en nuestra opinión, es aceptar la similitud del tratamiento elipsoide de estos jarritos del conjunto con el que presentan las peanas metálicas de candelabro números 95 a 97 (KHAMIS, 2013: 143-144) y los fustes con esta decoración incisa en sus nudos y en la columna de los ejemplares números 39 a 43, ambos inclusive (KHAMIS, 2013: 136), los cuales conforman el grupo de los candelabros de su tipo
"C", del que se ha encontrado un ejemplar en el Líbano y otro en el conjunto de Caesarea, de la primera mitad del siglo XI (ZIFFER, 1996:111, fg. 92; LESTER, et alii, 1999: 34). Datos que le llevan a defender el que estos candelabros hayan sido fundidos en el mismo Tiberiades (KHAMIS, 2013: 37). Jarritos y candelabros con este tratamiento que, por otro lado, no se han documentado en el conjunto de bronces fatimíes hallados en Denia (AZUAR, 2012; 2017).

Ahora bien, estos jarritos -realizados en Tiberiades y de época fatimí- tienen difícil encaje con los dos grandes subgrupos tipológicos descritos, siguiendo la clasificación de K. Werz (2005). Así, los jarritos de Tiberiades presentan un perfil de cuerpo, claramente piriforme, aunque sus bases planas los enlazan con los jarritos del subtipo "A" de la mencionada clasificación. Sin embargo, su tratamiento decorativo de un diseño inciso elipsoide -totalmente diferente al común facetado propio de este subtipo "A" - los llevaría o los acerca al subtipo "B", aunque sus cuerpos no corresponden al tipo "bulbiforme". Por otro lado, la presencia en el asa -de los ejemplares de Tiberiades-de un "ave" de talla y representación naturalista podría justificar su pertenencia o vinculación a este subtipo "B", pero su diseño se distancia claramente del tratamiento esquemático de los jarritos andalusíes.

Las diferencias expuestas, así como las similitudes formales, nos llevan a interpretar a estos jarritos de Tiberiades como piezas "mixtas" que por su hallazgo y desde su análisis arqueológico no hay dudas sobre su origen fatimí, aunque de producción sirio-palestina, y de una cronología contrastada de la segunda mitad del siglo XI. Piezas éstas de desarrollo "mixto" que podemos considerarlas -no por su tipo piriforme sino por su característica decoración del cuerpo con incisiones elipsoides y la interesante presencia de la figura de un "ave" como remate de la parte superior de sus asascomo precedentes de los jarritos andalusíes, aunque su análisis desde la mera perspectiva ornamental no nos permite, como se ha visto, establecer lazos directos tipológica y decorativamente. 
De igual forma y en la Península, la documentación arqueológica de los hallazgos de algunas de estas piezas nos permite avanzar en su datación contextual. Así sucede en el caso de jarrito de Bunyola (Mallorca) que apareció junto a un candil de pie alto de cuerpo tronco-cilíndrico o "gutiforme"10 y de doble piquera, candil clasificado por J. Zozaya como de su subtipo IVa (2010a:227), similar al hallado en el conjunto de la plazuela de Chirinos de Córdoba y al encontrado en la Calle Adarve, 18, de Córdoba. Candiles que, por su forma y por la datación epigráfica de este último, así como por su presencia en la Qal'a Banû Hammâd, se consideran como de la primera mitad del siglo XII o de época almorávide (ZOZAYA, 2010a: 227). Cronología que podemos aplicar a este jarrito de Bunyola y por extensión a los "bulbiformes" con decoración elipsoide del subtipo "B" de la clasificación de K. Werz (2005), desde criterios contextuales, como hemos tratado recientemente (AZUAR, 2019b).

Por otro lado y de igual forma, tenemos que referirnos a la cronología contextual y posterior almohade del jarrito de la plazuela de Chirinos de Córdoba, según el análisis epigráfico del conjunto (OCAÑA, 1985). Jarrito piriforme y de cuerpo facetado característico de los ejemplares del subtipo "A" de K. Werz (2005) y en el que también incluiríamos el jarrito hallado en la calle Cortés de Murcia, encontrado en un contexto arqueológico de pleno siglo XIII y cuyo estudio nos permite sugerir su autoría y origen ayubí (AZUAR, 2019). Dataciones arqueológicas que confirman la cronología tardía de estos ejemplares de jarritos del subtipo "A" y posterior a la de los jarritos del tipo "B" O "bulbiformes" hallados en la Península.

\section{CENTROS DE PRODUCCIÓN Y DATACIÓN}

Los datos aportados por la documentación arqueológica y contextual vienen a matizar las primeras hipótesis de identificación de estas piezas, tras el riguroso análisis e identificación de los jarritos hispano-visigodos realizado por Pedro de Palol que, por exclusión, propuso para estos jarritos un origen califal de tradición copta (1950, 1961-2). La arqueología nos permite aseverar que nos encontramos ante el grupo más numeroso de piezas, las del subtipo "B" de jarritos "bulbiformes", de exclusiva producción andalusí y muy seguramente -por su geografía de aparición- procedentes de talleres ubicados en Córdoba, aprovechando la tradición y la cercanía de las minas para el aprovisionamiento de los componentes metálicos necesarios para su fundición. Jarritos cuya forma y tratamiento decorativo se inspiran claramente en los bronces fatimíes de técnica mixta, producidos en el área sirio-palestina del imperio Fatimí en la segunda mitad del siglo XI y cuyas influencias pudieron llegar a Córdoba a finales del siglo XI, a través de Sicilia o del territorio Hammâdí del norte de África, para desarrollarse en al-Andalus y distribuirse exclusivamente por el Mediterráneo Occidental, seguramente en la primera mitad del siglo XII, bajo el dominio político de los almorávides (AZUAR, 2019b).

Por el contrario, los jarritos del tipo "A" constituyen el grupo más reducido, apenas compuesto por tres ejemplares: el jarrito de Valladolid, el hallado en la Plazuela de Chirinos (2019a) y el de la C/ Cortés de Murcia (AZUAR 2019). Así, son jarritos facetados de clara influencia de los ejemplares fatimíes alejandrinos pero en el ejemplar de jarrito hallado en el conjunto de la Plazuela de Chirinos de Córdoba se aprecia el sello propio y diferenciador de su tradición andalusí, presente exclusivamente en su exuberante decoración con presencia de zoomorfos en su cuerpo, lo que refuerza su origen cordobés, aunque -en atención a su cronología epigráfica contextual- sería de finales del siglo XII y arqueológicamente anterior a la conquista de la ciudad de Córdoba acaecida en 1236. Por el contrario, el jarrito procedente de la Calle Cortés de Murcia por su estilizado diseño y por ser el único de los hallados en la Península con franja epigráfica, sugiere el que lo consideremos como un ejemplar no anda-

10. Término no recogido en el diccionario de la R.A.E., pero utilizado por J. Zozaya para la descripción de estos candiles (2010a). 
lusí sino importado a mediados del siglo XIII del Egipto Ayubí (AZUAR 2019).

En conclusión y a la vista de los datos expuestos, podemos afirmar que este tipo de jarritos con tapadera y asa acodada -y en concreto los del subtipo B o "bulbiformes"- aparecen en al-Andalus a finales del siglo XI, claramente influidos por los jarritos fatimíes de procedencia de los talleres ubicados en sus territorios sirio-palestinos. Tipología de jarritos sin precedentes en la metalistería andalusí, es decir sin relación formal alguna con los jarritos aguamaniles considerados como de época taifa o del siglo XI, como serían el que se conserva en el Museo Arqueológico Nacional ( $n^{\circ}$ Inv. 1966/10/2) (MAKARIOU, 2000-2001a: 152, n 169; ZOZAYA, 2001: 209) y en la David Collection ( $n^{\circ}$ inv. 5/1990) (ROBINSON, 1992:214-5, nº 14; MAKARIOU, 2000-2001: 151, no 168). Jarros de cuerpo piriforme pero cuyas asas, su pico vertedor y su decoración zoomorfa los diferencia claramente de este tipo de jarritos.

Más aún, no se sostiene el argumento defendido por K. Werz sobre los precedentes no andalusíes sino romanos de estos jarritos (2005: 25), con base en su similitud formal con el jarrito tipo Blechkannen, de perfil piriforme, con base plana y borde trilobulado, con asa que los divide entre los que la tapadera va fundida al borde o al asa, producido en Galia, Germania y Britania durante el Alto Imperio. Jarritos ya revisados por Romana Erice al estudiar la vajilla de bronce en Hispania (2007), en el que se remitía a los contados ejemplares publicados por J. Aurrecoechea (1991) y al jarrito encontrado en Conimbriga, publicado por A. Alarçao (1996) de una amplia cronología que puede alargarse a los siglos V-VI d.C. Contado número de ejemplares peninsulares y de una cronología muy distante a la de nuestros jarritos islámicos que hacen muy difícil el mantener la hipótesis de su precedente directo, más teniendo en cuenta que en medio tenemos el alto número de jarritos hispanovisigodos que analizara P. Palol-cuyo registro se ha visto ampliado por el trabajo posterior de L. Balmaseda y C. Papi (1998)- cuya presencia y diferencias tipológicas lo llevaron a proponer la creación de un subgrupo de época califal, donde incluyó estos jarritos, de uso litúrgico y de tradición copta (PALOL, 1950, 1961-1962).

En conclusión, jarritos piriformes con tapadera y asa acodada de cuerpo "bulbiforme" de producción andalusí, de finales del siglo XI, primera mitad del siglo XII, que se expandirán por el Mediterráneo Occidental bajo el dominio político Almorávide y -a la vista de los ejemplares conocidos- desaparecerán a finales del siglo XII, dando paso a los jarritos piriformes de cuerpo "facetado" del tipo "A" -como el depositado en Valladolid o el aparecido en la plazuela de Chirinos de Córdoba- de clara tradición copta fatimí, pero procedentes de talleres cordobeses -atendiendo a su tratamiento decorativo de tradición andalusí- que desaparecerán a mediados del siglo XIII con el avance de la conquista cristiana, en un contexto cronológico tardío y pre-nazarí en el que podemos hallar piezas singulares como el jarrito ayubí, importado de Egipto y hallado en la ciudad de Murcia.

\section{BIBLIOGRAFÍA}

ALARÇAO, A. (1996): "O jarro metálico tipo Eggers 128, antecedentes, variantes e imitaçoes", Miscellanea em Homenagen ao Profesor Bairrao Oleiro, Lisboa pp. 25-37.

ALI, W. (1999): The Arab contribution to islamic Art: from the Seventh to the Fifteenth Centuries. El Cairo: The American University in Cairo.

ALLAN, J.W. (1976): The Metalwork Industry in Iran in the early Islamic Period. Oxford. (Tesis doctoral).https:// ora.ox.ac.uk/objects/uuid:278c6978-9421-46af-af61a062a2044591, [consultada en junio 2018]

- (1976-7): "Silver: the key to bronze in early Islamic Iran", Kunst des Orients, XI, nº 1-2, pp. 5-21.

- (1979): Persian Metal Technology 700-1300 AD, Oxford: Ithaca Press

- (1982): Nishapur: Metalwork of the early period. Nueva York: the Metropolitan Museum of Art.

- (1986): Metalwork of the Islamic World. The Aron Collection. Londres: Philip Wilson Publishers.

ALMAGRO GORBEA, M. (1966): "Nuevo Grupo de Jarritos Litúrgicos de Tipo Copto Procedentes de Cerdeña”, Boletín del Seminario Estudios de Arte y Arqueología, 32, pp. 367-380.

AURRECOECHEA, J. (1991): "Vajilla metálica de época romana en los museos de Ciudad Real, Jaén y Linares", 
Espacio, tiempo y forma, serie II- $H^{a}$ Antigua, 4 (Madrid), pp. 223-254.

AZUAR RUIZ, R. (2012): Los bronces islámicos de Denia (S.V HG/XIDC), Alicante: MARQ. Museo Arqueológico.

- (2017): "Los bronces Fatimíes de Denia (siglo XI D.C.)", en Susana CALVO CAPILLA (Ed.): Las Artes en al-Andalus y Egipto. Contextos e Intercambios, Madrid, pp. 45-68.

- (2019): "La redoma islámica de bronce del Museo de Santa Clara de Murcia (s. XIII d.C.)”, Tudmîr, 5, pp. 73-83.

- (2019a): "El jarrito metálico con tapadera de la plazuela de Chirinos (Córdoba) (siglos XII-XIII d.C.)", en AL-KITÂB. Estudios en homenaje a Juan Zozaya Stabel-Hansen, Madrid, pp. 437-441.

- (2019b): "Bronces andalusíes de época Almorávide", Actas de las Jornadas internacionales Arqueología de al-Andalus Almorávide, Alicante: MARQ. Museo Arqueológico (e.p.).

BAER, E. (1983): Metalwork in Medieval Islamic Art, Nueva York: Suny Press.

BARROCAND, M. (Ed.) (1999): L'Egypte Fatimide son Art et son Histoire, París: Institut du Monde Árabe. Catálogo.

BASS, G. F.; MATTHEWS, S. D. ; STEFFY, J. R. y VAN DOORNINCK, F. H. Jr. (2003): Serçe Limani. An Eleventh-century Shipwerck I. The Ship and Its anchorage, Crew, and Passengers, College Station: Texas A \& M University Press.

BASS, G. F.; BRILL, R. H.; LLEDÓ, B. y MATTTHEWS, S. D. (2009): Serçe Limani. II The Glass of an eleventh-Century shipwreck. College Station: Texas A \& M University Press.

BRISCH, K.; GLADIS, A. V.; KRÖGER, J. y NIEWHNER, E. (1986): Islamische Kunst Verborgene Schätze, Berlín: Museums für Islamische Kunst.

CALVO CAPILLA, S. (Ed.) (2017): Las Artes en al-Andalus y Egipto. Contextos e Intercambios, Madrid: La Ergástula S.L.

Córdoba (2001): El esplendor de los Omeyas cordobeses, Córdoba: El Legado Andalusí, Catálogo.

DAHNCKE, M. (1997): Enghalsflaschen Typologie Früislamischer Bronzen der Bumiller-Collection, Band-5, Bamberg: Bumiller-Collection.

DALTON, O. M. (1901): Catalogue of early Christian Antiquities and Objects from the Christian East, Londres: British Museum. https://ia601407.us.archive.org/11/items/catalogueofearly00brit/catalogueofearly00brit.pdf [Consultado, junio de 2018].

DELIBES DE CASTRO, G.; PÉREZ, F.; WATTENBERG, E. (1996): Guía. Colecciones Museo de Valladolid. Valladolid: Junta de Castilla y León.

EGUARAS, J. (1952-1953): "Donativo de Don Manuel Gómez-Moreno Martínez", Memoria de los Museos Arqueológicos Provinciales, XIII-XIV, pp. 45-47.

ELORZA, J.C. (Dir.) (2007): El Cid, del hombre a la leyenda [Burgos, 2007]. Madrid: Junta de Castilla y León. Catálogo.
ERICE LACABE, R. (2007): "La vajilla de bronce en Hispania”, Sautuola, XIII: 197-215.

ETTINGHAUSEN, R. (1943): Metalwork from Islamic countries. Exhibition Rackham Building, Michigan: Institute of Fine Arts. Catálogo.

-(Com.) (1981): The Arts of Islam. Berlín: Staal. Museem. Catálogo.

FEHÉRVÁRI, G. (1976): Islamic Metalwork of the Eighth to the fifteenth Century in the Keir Collection. Londres: Faber \& Faber.

GÓMEZ-MORENO, M. (1951): El Arte Árabe español hasta los almohades. Arte Mozárabe, Ars Hispaniae, III, Madrid: Ed. Plus-Ultra.

GONZÁLEZ CAVERO, I. (2010): "Jarrito Califal”, en M. PÉREZ et alii. (Coords): In principio erat verbum. El Reino de León y sus beatos [León, 2010)]. Madrid: Sociedad Estatal de Conmemoraciones Culturales. Catálogo.

Granada (1992): Al-Andalus. Las artes islámicas en España, Granada-Nueva York: Ed. El Viso. Catálogo.

Haifa (1999): The Richness of Islamic Caesarea, Haifa: Reuben and Edith Hecht Museum-University of Haifa. Catálogo.

HIRSCHFELD, Y.; UTFELD, O. (2008): Tiberias excavations in the House of Bronzes. Final Reports. Vol. I. Architecture, Stratigraphie and Small finds, QEDEM, 48, Jerusalén: The Hebrew University of Jerusalem.

KHAMIS, E. (2012): "The Fatimid bronze hoard of Tiberias", en PORTER, V.; ROSSER-OWEN, M. (Ed.): Metalwork and material culture in the Islamic world. Art, craft and text. Londres-Nueva York: I.B. Tauris, pp. 223-238.

-(2013): The Fatimid metalwork hoard from Tiberias. Tiberias: excavations in the house of the bronzes. Final report, vol. II. The Institute of Archaeology, QEDEM, 55. Jerusalén: The Hebrew University of Jerusalem.

KHAMIS, E. y AMIR, R. (1999): "The Fatimid Period Bronze Vessel Hoard”, Qadmoniot, XXXII/2: 108-114 (en Hebreo).

LAVIOLA, V. (2016): Metalli islamici dai territori Iranici orientali (IX - XIII sec.) La documentazione della Missione Archeologica Italiana in Afghanistan. Venecia: Universitá Ca'Foscari (Tesis Doctoral). http://dspace.unive.it/bitstream/handle/10579/8349/956008-1175887.pdf?sequence=2 [consultado, julio de 2018].

LESTER, A. (1999): "The Metal Hoard of Caesarea", en The Richness of Islamic Caesarea, Haifa, pp. 36-41.

LESTER, A.; ARNON, Y. D. y POLAK, R. (1999): "The Fatimid Hoard from Caesarea: a Preliminary Report", en BARROCAND, M. (Ed.): L'Egypte Fatimide son Art et son Histoire, París, pp. 233-248.

Lisboa (1998): Portugal islámico. Os últimos sinais de Mediterrâneo, Lisboa: Museu Nacional de Arqueologia. Catálog.

Madrid (1959): Exposición antológica del tesoro documental, bibliográfico y arqueológico de España. Madrid: Ministerio de Educación Nacional. 
MAKARIOU, S. (2000-2001): "Aguamanil”, Las Andalucías de Damasco a Córdoba, (París), pp. 151 n 168.

-(2000-2001a): Catálogo "Aguamanil”, Las Andalucías de Damasco a Córdoba, (París), pp. 152 nº 169.

MARTíNEZ, Ma A.; ROBLES, A. (2008): "Redoma", en Regnum Murciae: Génesis y configuración del Reino de Murcia. Murcia: 377

MELIKIAN-CHIRVANI, A.S. (1973): Le bronze Iranien. París: Musée des Arts Décoratifs.

- (1976): Islamic Metalwork from Iranian Lands. Londres: Victoria and Albert Museum.

- (1982): Islamic Metalwork from the Iranian World. 8th18th centuries. Londres. Victoria and Albert Museum.

MIGEON, G. (1927): Manuel d'Art Musulman. Arts Plastiques et Industrials. París: Ed. Picard. II vols.

MUÑOZ LÓPEZ, F. (1994): “Calle Cortés 13, 15 y 21" ", V Jornadas de Arqueología Regional, Murcia: Región de Murcia, s.p.

- (1999). "Sobre la evolución de una manzana de casas andalusíes en Murcia", Memorias de Arqueología, 8, pp. 416-436.

MUÑOZ LÓPEZ, F. y NAVARRO PALAZÓN, J. (1994): “C/ Cortés, 13-17", IV Jornadas de Arqueología Regional, Murcia: Región de Murcia, s.p.

Murcia (2008): Regnum Murciae. Génesis y configuración del Reino de Murcia. Murcia: Museo Arqueológico. Catálogo.

NEBREDA MARTIN, L. (2017): Documentación sobre Arte y Arqueología en el Instituto Valencia de Don Juan. Análisis de la colección andalusí a través de sus documentos. Madrid: Universidad Complutense. Tesis doctoral. https:// core.ac.uk/download/pdf/85158409.pdf

OCAÑA JIMÉNEZ, M. (1985): "Los supuesto bronces califales del Museo Arqueológico Provincial de Córdoba”, Actas de las II Jornadas de Cultura Árabe e Islámica (1980), Madrid, pp. 405-417.

ORSI, P. (1942): "Bicchiere-misura in rame, siglato. Vasetto”, Sicilia Bizantina, (Roma), p. 180, Lám. XII-b.

PALOL SALELLAS, P. de (1950): Bronces hispano-visigodos de origen mediterráneo: Jarritos y patenas litúrgicas. Barcelona: Consejo Superior de Investigaciones Científicas.

- (1961-1962): "Los bronces litúrgicos hispano-visigodos y sus perduraciones", Homenaje al Prof. Cayetano de Mergelina, Murcia, pp. 699-710.

PÉREZ RODRÍGUEZ, F. (1997): “Jarrito Califal", en DELIBES DE CASTRO, G.;PÉREZ RODRÍGUEZ, F. y WATTENBERG GARCÍA, E. (1996): Guía. Colecciones Museo de Valladolid. Valladolid, p. 169.
-(2007): “Jarrito Califal", en ELORZA, J.C. (Dir.): El Cid, del hombre a la leyenda [Burgos, 2007]. Madrid, p. 86.

PÉREZ GONZALEZ, M.; REGLERO DE LA FUENTE, C. M. y TORRES, M. (Coords.) (2010): In principio erat verbum. En El Reino de León y sus beatos (León, 2010)]. Madrid: Sociedad Estatal de Conmemoraciones Culturales. Catálogo.

PORTER, V. y ROSSER-OWEN, M. (Eds.) (2012): Metalwork and material culture in the Islamic world. Art, craft and text. Londres-Nueva York: I.B. Tauris.

ROBINSON, C. (1992): “Jarra”, Al-Andalus. Las artes islámicas en España, Granada-Nueva York, pp. 214-5, nº 14.

ROSSELLÓ BORDOY, G. (1962): "Bronces árabes de Mallorca", Al-Andalus, XXVII, n¹1, pp. 229-233.

SANTOS JENER, S. de los (1955-1957): "Las piezas árabes de latón de la Plazuela de Chirinos", Memorias de los Museos Arqueológicos Provinciales, XVI-XVIII, pp. 190-193, Lam. XXXV-XL.

- (1961-2): "Hallazgo arqueológico de braserillos y otras piezas. Las industrias califales y las obras salomoniegas de Córdoba", Al-Mulk, 2, pp.183-191.

STRZYGOWSKI, J. V. (1904): Catalogüe general des antiquites egyptiennes du Musee du Caire. Koptische Kunst. Viena: Service des Antiquitès de l'Égypte.

TORRES BALBÁS, L. (1987): Arte Hispanomusulmán hasta la caída del califato de Córdoba., V. España Musulmana, Madrid: Espasa-Calpe S.A., $5^{\text {a }}$ ed.: pp. 331-788.

WARD, R. (1993): Islamic Metalwork. Londres: British Museum Press.

WERZ, K. (2005): "Sogenanntes koptisches". Buntmetallgeschirr: eine methodische und analytische untersuchung zu den als koptisch bezeichneten buntmetallgefäßen, Constanza: Universität Frankfurt am Main. (Tesis doctoral) https://docplayer.org/42965853-Sogenanntes-koptisches-buntmetallgeschirr.html,

[consultado junio 2018].

ZIFFER, I. (1996): Islamic Metalwork. Tel Aviv: Eretz Israel Museum. Catálogo.

ZOZAYA STABEL-HANSEN, J. (1993): "Importaciones casuales en al-Andalus: las vías de comercio", IV Congreso de Arqueología Medieval Española, I, pp. 119-138

- (2001): “Jarro/Aguamanil”, en El esplendor de los Omeyas cordobeses, Córdoba, pp.209.

- 2010): "Aeraria de Transición: objetos con base de cobre de los siglos VII al IX en al-Andalus", Arqueologia Medieval, 11, pp. 11-24.

-(2010a): "Candiles metálicos andalusíes", Boletín de Arqueología Medieval, 14, pp. 197-258. 